\title{
Inosine Augments the Effects of a Nogo Receptor Blocker and of Environmental Enrichment to Restore Skilled Forelimb Use after Stroke
}

\author{
Laila Zai, ${ }^{1,2,4}$ Christina Ferrari, ${ }^{1}$ Carlie Dice, ${ }^{1}$ Sathish Subbaiah, ${ }^{1,4}$ Leif A. Havton, ${ }^{5}$ Giovanni Coppola, ${ }^{5,6}$ \\ Daniel Geschwind, ${ }^{5,6}$ Nina Irwin, ${ }^{1,2,4}$ Eric Huebner, ${ }^{7}$ Stephen M. Strittmatter, ${ }^{7}$ and Larry I. Benowitz ${ }^{1,2,3,4}$ \\ ${ }^{1}$ Laboratories for Neuroscience Research in Neurosurgery and ${ }^{2}$ F. M. Kirby Neurobiology Center, Children's Hospital, Boston, Massachusetts 02115 , \\ ${ }^{3}$ Program in Neuroscience and ${ }^{4}$ Department of Surgery, Harvard Medical School, Boston, Massachusetts 02115, ${ }^{5}$ Department of Neurology and \\ ${ }^{6}$ Neurogenetics Program, University of California, Los Angeles, Los Angeles, California 90095, and ${ }^{7}$ Department of Neurology, Yale University School of \\ Medicine, New Haven, Connecticut 06520
}

Stroke is the leading cause of disability in much of the world, with few treatment options available. Following unilateral stroke in rats, inosine, a naturally occurring purine nucleoside, stimulates the growth of projections from the undamaged hemisphere into denervated areas of the spinal cord and improves skilled use of the impaired forelimb. Inosine augments neurons' intrinsic growth potential by activating Mst3b, a component of the signal transduction pathway through which trophic factors regulate axon outgrowth. The present study investigated whether inosine would complement the effects of treatments that promote plasticity through other mechanisms. Following unilateral stroke in the rat forelimb motor area, inosine combined with NEP1-40, a Nogo receptor antagonist, doubled the number of axon branches extending from neurons in the intact hemisphere into the denervated side of the spinal cord compared with either treatment alone, and restored rats' level of skilled reaching using the impaired forepaw to preoperative levels. Similar functional improvements were seen when inosine was combined with environmental enrichment (EE). The latter effect was associated with changes in gene expression in layer 5 pyramidal neurons of the undamaged cortex well beyond those seen with inosine or EE alone. Inosine is now in clinical trials for other indications, making it an attractive candidate for the treatment of stroke patients.

\section{Introduction}

Stroke represents the leading cause of disability and third leading cause of death in the United States and many other countries (Dobkin, 2003). A limited amount of recovery often occurs in the first weeks or months after stroke and is associated in part with functional changes in brain regions adjacent to, or interconnected with, damaged areas (Dobkin, 2003; Cramer and Crafton, 2006; Cramer, 2008a). Similar changes are seen in animal models of stroke, and correlate with dendritic remodeling and alterations in axonal projections (Jones and Schallert, 1994; Carmichael et al., 2001; Carmichael, 2003; Dijkhuizen et al., 2003; Conner et al., 2005; Dancause et al., 2005; Nudo, 2007; Brown et al., 2008,

Received Aug. 26, 2010; revised Feb. 17, 2011; accepted Feb. 19, 2011.

Author contributions: L.Z., S.M.S., and L.I.B. designed research; L.Z., C.F., C.D., S.S., L.A.H., G.C., N.I., and E.H. performed research; G.C. and D.H.G. contributed unpublished reagents/analytic tools; L.Z., C.F., L.A.H., G.C., D.H.G., E.H., and L.I.B. analyzed data; L.I.B. and L.Z. wrote the paper.

We are grateful for the support of the National Institutes of Health (NIH) (Grant R01 NS047446 to L.B.; Grant NS39962 to S.M.S.), the Dr. Miriam and Sheldon G. Adelson Medical Research Foundation, and Alseres Pharmaceuticals. We thank the Developmental Disabilities Resource Center of Children's Hospital (NIH Grant P3O HD018655) for use of the Histology and Image Analysis Cores; Charles Vanderberg and the Laser Capture Core Facility of the Harvard Center for Neural Discovery; Jing Ou and Fuying Gao for assistance with microarray experiments; and Judith Li, Haleh Hashemi, and Melissa Hootstein for animal training and testing.

Correspondence should be addressed to Dr. Larry I. Benowitz, Laboratories for Neuroscience Research in Neurosurgery, Children's Hospital, 300 Longwood Avenue, Boston MA 02115. E-mail: larry.benowitz@childrens. harvard.edu.

DOI:10.1523/JNEUROSCI.4498-10.2011

Copyright $\odot 2011$ the authors $\quad 0270-6474 / 11 / 315977-12 \$ 15.00 / 0$
2009). Although the precise relationship between the anatomical and behavioral changes remains uncertain, several agents that enhance anatomical reorganization have been shown to improve outcome in animal models of stroke (Cramer, 2008b; Benowitz and Carmichael, 2010).

One such agent is inosine, a naturally occurring purine nucleoside. Inosine diffuses across the cell membrane and activates Mst3b, a protein kinase involved in the signal transduction pathway through which trophic factors stimulate axon growth (Irwin et al., 2006; Lorber et al., 2009). Following unilateral stroke or traumatic brain injury in rats, inosine enhances the ability of neurons in the undamaged hemisphere to extend axon collaterals into brainstem and spinal cord areas that have lost their normal innervation and improves fine motor control with the impaired limb (Chen et al., 2002; Smith et al., 2007; Zai et al., 2009).

Manipulations that counteract myelin-associated inhibitors of axon growth represent an alternative way to improve outcome after stroke. Antibodies to Nogo-A or agents that block signaling through the Nogo receptor $(\mathrm{NgR})$ promote the formation of novel corticospinal tract (CST) projections after stroke and improve use of the impaired forelimb (Papadopoulos et al., 2002; Lee et al., 2004; Tsai et al., 2007). Because these approaches induce plasticity by counteracting cell-extrinsic factors, we investigated whether inosine, an activator of neurons' intrinsic growth potential, would augment the structural and behavioral effects of an $\mathrm{NgR}$ antagonist after stroke. 
Poststroke recovery can also be enhanced by environmental enrichment (EE) (Ohlsson and Johansson, 1995; Johansson and Ohlsson, 1996; Biernaskie and Corbett, 2001; Fischer et al., 2007). Because physical activity is a standard component of poststroke recovery, we also investigated whether inosine would augment the effects of EE. Our results show that inosine combined either with a Nogo receptor antagonist or EE restores rats' success in a skilled-reaching task to preoperative levels using the impaired forepaw.

\section{Materials and Methods}

Stroke surgery. All procedures were performed in accordance with National Institutes of Health guidelines and with the approval of Children's Hospital Animal Care and Use Committee. Adult male Sprague Dawley rats (275-300 g; Charles River Laboratories) were maintained on a $12 \mathrm{~h}$ light/dark cycle (lights on at 7:00A.M.). Surgery was performed between 8:30 A.M. and 3:00 P.M., with animals from different experimental groups intermingled. Strokes were centered in the right caudal forelimb motor area and included varying amounts of adjacent cortical areas (Zai et al., 2009). Rats were anesthetized with ketamine $(75 \mathrm{mg} / \mathrm{kg})$ and Domitor (medetomidine; $0.5 \mathrm{mg} / \mathrm{kg}$ ), the skin was incised along the midline, muscles and skin were retracted, and a craniotomy was performed to create a rectangular window that extended mediolaterally from the sagittal sinus to the temporal ridge, and rostro-caudally between bregma $+3.5 \mathrm{~mm}$ and $-2.5 \mathrm{~mm}$. Rose Bengal, a photosensitive dye, was injected into the femoral vein through a small opening in the inner thigh. A fiber-optic cable connected to a xenon light source was positioned over the craniotomy, focusing light directly on the exposed region of the brain to activate Rose Bengal for $30 \mathrm{~min}$. A green filter restricted illumination to $\sim 525 \mathrm{~nm}$. Under these conditions, Rose Bengal releases free radical species that damage endothelial cells in the exposed portions of the cortical vasculature, resulting in platelet aggregation and focal ischemia. Alzet minimpumps were tucked between the shoulder blades, and infusion needles were secured onto the cranium with a silicon-based glue. Incisions were closed with 3-0 silk sutures and cleaned with betadine and ethanol pads. Animals were kept on a warming pad during and after surgery, and were returned to their cages when fully awake, mobile, and able to thermoregulate (as judged by absence of piloerection). For $3 \mathrm{~d}$ following surgery, animals received twice-daily subcutaneous injections of Buprenex (buprenorphine, Reckitt Benkiser Pharmaceuticals) for pain management. Animals in the first study were randomly assigned to receive continuous infusion of saline $(0.9 \%$, Baxter Scientific), inosine (50 mu in saline, Sigma-Aldrich), NEP1-40, a Nogo receptor antagonist (500 $\mu \mathrm{M}$ in $2.5 \% \mathrm{DMSO} / 97.5 \%$ saline), or inosine plus NEP1-40 into the lateral ventricle of the undamaged hemisphere via osmotic minipumps $(0.25 \mu \mathrm{l} / \mathrm{h}$, Alzet model 2004, Durect Corporation). To achieve rapid drug build-up in the CSF, animals in all studies received a $25 \mu \mathrm{l}$ intraventricular bolus of the agent to be infused before pump placement. Treatments were assigned randomly before surgery. Unless noted otherwise, rats were housed in pairs.

The study examining the interactions of inosine and NEP1-40 included two behavioral experiments, one in which rats survived for 4 weeks after stroke and another in which they survived for 8 weeks. In the 4 week study, rats treated with either NEP1-40 alone $(N=11)$ or NEP1-40 plus inosine $(N=11)$ were generated concurrently with animals reported in another study (Zai et al., 2009), but were not themselves described previously. Another group of rats, treated either with inosine alone $(N=7)$ or saline $(N=7)$, were generated specifically for this study. Post hoc analysis revealed that the behavioral and anatomical effects of inosine and saline were nearly identical between the newly generated cases and the ones reported on earlier, justifying our combining the newly generated inosine- and saline-treated animals with the previously generated animals treated with NEP1-40. Animals in the 8 week study treated with NEP1-40, either with or without inosine $(N=11$ for each), have not been described earlier but were also generated concurrently with saline- and inosine-treated animals reported in a previous study (Zai et al., 2009). Behavioral testing was performed during daylight hours, with no systematic bias toward type of treatment.
Environmental enrichment. Following pretraining and surgery, animals for anatomical and behavioral studies were implanted with minipumps delivering either saline $(N=21)$ or inosine $(N=20)$ and were housed in pairs in standard cages. Three days later, half the rats in each treatment group were selected at random and transferred to specially designed chambers for EE. The effects of brain injury can be exacerbated by physiological activity within the first week (Humm et al., 1999), although delaying exposure to EE by just 1-3 d enables the beneficial effects of EE to manifest themselves (Ohlsson and Johansson, 1995; Risedal et al., 2002; Dahlqvist et al., 2004). The EE chamber was a Plexiglas cube 24 inches on a side with fixed ladders and a platform to stand on, along with a set of tunneling tubes, toys, and treats that varied daily. At any given time, the chamber contained four to eight rats, with enough plastic tunnels for each rat to have its own. Rats had free access to water throughout the study and, with the exception of the day before behavioral testing, free access to standard rat chow. For the microarray studies, rats were housed individually for $3 \mathrm{~d}$ and then either transferred to the EE chambers or left in isolation for 4 more days before preparing tissue for analysis (see below, Microarray studies).

Behavioral testing. Rats were tested for their ability to reach through a narrow slit, retrieve food pellets (Bio-Serv) from a platform, and bring them successfully to their mouth (Allred and Jones, 2004; Luke et al., 2004). Variants of this task are widely used in the field because of its established reliance on the integrity of the motor cortex and descending cortical pathways, and because the results are readily quantified. In addition, the task mimics an essential feature of motor strokes in humans by evaluating performance on an acquired ability that requires precise motor control. In the acquisition phase, rats were maintained for $3 \mathrm{~d}$ before and during training on a diet restricted to the banana-flavored pellets used for the retrieval task. Rats were trained daily for 30-60 min with each paw for 2 weeks or until they attained a baseline performance of $20-30$ successful reaches in a 2 min period. Immediately after reaching this criterion, each animal was tested for the number of pellets it grasped successfully and consumed in two 2 min trials. The average of these became the baseline to which subsequent scores were normalized. Rats had free access to food and water for at least $3 \mathrm{~d}$ between baseline testing and surgery. Postoperative testing was performed in 10-20 min sessions at $7,14,21$, and $28 \mathrm{~d}$ after surgery by an experimenter blind to the animals' treatment. Performance was evaluated in two 2 min blocks using each paw. Scores were recorded only if animals were able to perform at or near their preoperative level with the unimpaired paw. In instances in which this did not occur immediately, we waited until rats were more active to test them again. In the 8 week studies, rats were tested weekly as above for 4 weeks while receiving the various agents, and then for an additional 4 weeks after the minipumps and catheters were removed. Data were analyzed using a two-way ANOVA (repeat measures) with Bonferroni's post-test to compare datasets.

Anterograde tracing of crossing fibers. At the completion of behavioral testing, rats were reanesthetized, the infusion needle and pump were removed, and a craniotomy was performed over the uninjured sensorimotor cortex (SMC). Biotinylated dextran amine (BDA) (10,000 molecular weight, $10 \% \mathrm{w} / \mathrm{v}$ solution in sterile saline; Invitrogen) was used as an anterograde tracer and was injected stereotaxically at depths of $0.5,1.0$, and $2.0 \mathrm{~mm}$ below the cortical surface at 18 standardized points covering most of the caudal forelimb motor area (70 $\mathrm{nl}$ per injection; Nanoject, Drummond Scientific). Stereotaxic coordinates of the injection sites are shown in supplemental Table 1 (available at www.jneurosci.org as supplemental material). Two weeks later, animals were anesthetized and perfused transcardially with $0.9 \%$ saline followed by $4 \%$ paraformaldehyde. The brain and spinal cord were dissected and postfixed in the same fixative for $1 \mathrm{~h}$ at room temperature and overnight at $4^{\circ} \mathrm{C}$, then transferred successively to 10 and $30 \%$ sucrose solutions $\left(4^{\circ} \mathrm{C}\right)$ over the next few days. Tissue was embedded in OCT Tissue Tek Medium (Sakura Finetek USA) and frozen on dry ice. Forty micrometer free-floating sections were cut in the coronal plane on a Frigo-Jung 8500 cryostat and stained with avidin-biotin complex conjugated to horseradish peroxidase (Vectastain ABC Kit, Vector Laboratories) followed by Vector SG (Vector) as a chromagen. Sections were mounted on slides (Super Frost plus, Fisher) and lightly counterstained with eosin to distinguish gray and 
white matter boundaries. Six to ten equally spaced sections spanning a distance of $1.2 \mathrm{~mm}$ were examined and quantified for (1) axons within the dorsal funiculus (BDA-labeled axon profiles $\geq 40 \mu \mathrm{m}$ in length in the transverse plane within the dorsal funiculus on the denervated side of the spinal cord); (2) axons within the gray matter (as above, but within the gray matter on the denervated side); and (3) lengthy axons in the gray matter (as above, but $\geq 200 \mu \mathrm{m}$ in length in the transverse plane). Average numbers of axons were calculated, and numbers were converted to axons per millimeter length of spinal cord. Bouton-like structures were identified under a $100 \times$ oil objective as regions $>2 \times$ the thickness of the axon shaft. Counts were performed in a $0.5 \mathrm{~mm}^{2}$ box aligned with laminae VI/VII, and were not extrapolated to any volumetric totals. Camera lucida drawings were performed using representative spinal cord sections from control and treatment groups. Statistical significance was determined by one-way ANOVA followed by Tukey's multiple comparisons test to evaluate significance between treatment groups.

Determination of lesion severity. Lesion sizes were calculated from serial sections through the telencephalon as described previously (Zai et al., 2009). Lesions were redrawn onto standard sections from the rat brain atlas (Paxinos and Watson, 1986) using gray/white matter boundaries and standard structures. Representations of the injury were created from tracings of scanned sections in Adobe Photoshop.

Cortical regeneration assay. Primary cortical cultures were established from embryonic day 18 (E18) Sprague Dawley rat brains. All tissue culture reagents were from Invitrogen unless otherwise stated. Brains were dissected in Hibernate E without calcium (BrainBits LLC) supplemented with B-27, 1 mu sodium pyruvate, and $10 \mu \mathrm{g} / \mathrm{ml}$ gentamicin (dissection medium). Reagents and brains were kept on ice except during the initial dissection. Meninges were removed, and cortices were dissected and combined in a $10 \mathrm{~cm}$ Petri dish in $1 \mathrm{ml}$ of dissection medium. Tissue was diced $\sim 100$ times into small pieces with a razor blade. Dissection medium (12 ml) containing papain ( $4.2 \mathrm{mg} / \mathrm{ml}$; P4762, Sigma) and DNase $(0.8 \mathrm{mg} / \mathrm{ml})$ were added to the Petri dish, which was then placed on an orbital shaker (11-671-50Q, Fisher Scientific) in a $37^{\circ}$ incubator (without $\mathrm{CO}_{2}$ regulation) and shaken at $30 \mathrm{rpm}$ for $1 \mathrm{~h}$. The dish was removed from the incubator, and the medium was transferred to a $15 \mathrm{ml}$ polystyrene Falcon tube on ice. Chunks of cortex were allowed to settle to the bottom of the tube for 1-2 min. The medium was removed, and chunks were resuspended in $1.5 \mathrm{ml}$ of dissection medium plus 10\% FBS and triturated 10-15 times with a fire-polished Pasteur pipette. Medium containing dissociated cortices was transferred to another $15 \mathrm{ml}$ tube containing $12.5 \mathrm{ml}$ of dissection medium plus $10 \%$ FBS and centrifuged at $600 \times g$ for $6 \mathrm{~min}$ at $4^{\circ} \mathrm{C}$. The supernatant was removed, and cells were resuspended in $12 \mathrm{ml}$ of Neurobasal A supplemented with B-27, $1 \mathrm{~mm}$ sodium pyruvate, $0.5 \mathrm{~mm}$ GlutaMAX-I, and $10 \mu \mathrm{g} / \mathrm{ml}$ gentamicin (in Neurobasal A plus supplements). Cells were filtered through a $70 \mu \mathrm{m}$ cell strainer into a $50 \mathrm{ml}$ Falcon tube and counted. Cells were removed from ice and diluted to $3.33 \times 10^{5}$ cells $/ \mathrm{ml}$ in Neurobasal A plus supplements, which had been prewarmed and pre-equilibrated in a $37^{\circ}$ tissue culture incubator $\left(5 \% \mathrm{CO}_{2}\right)$. Cells were plated at a density of $1.2 \times 10^{5} \mathrm{cells} / \mathrm{cm}^{2}$ $\left(4 \times 10^{4}\right.$ cells/well in $\left.120 \mu \mathrm{l}\right)$ in 96 well plates coated with poly-D-lysine (BD BioCoat, Becton Dickinson Labware). Door openings over the ensuing $21 \mathrm{~d}$ were kept to a minimum. At 7 and $14 \mathrm{~d}$ in vitro (DIV), cultures were fed by replacing $50 \%$ of the medium with fresh, prewarmed and pre-equilibrated Neurobasal A plus supplements. At 21 DIV, cultures were injured by scraping with a 96 well floating pin tool with FP1-WP custom parylene-coated pins $(0.557 \mathrm{~mm}$ tip diameter $)$. To guide the movement of the pin tool, a library copier (VP 381NW4.5, V\&P Scientific) with vertical alignment holes was used. Aluminum guide rails were added on the left and right of the library copier (Electronic and Machine Shop, Yale University School of Medicine, New Haven, CT) to minimize lateral movement of the pin tool. Immediately after the scrape, $50 \%$ of the medium was replaced with fresh medium. In some cases, the fresh medium contained extracted bovine CNS myelin (Cafferty et al., 2010) and/or agents to be tested. Cultures were returned to the incubator to regenerate neurites for $5 \mathrm{~d}$.

At 26 DIV, cultures were fixed by adding $100 \mu \mathrm{l} /$ well $4 \%$ paraformaldehyde plus $20 \%$ sucrose in PBS for $20 \mathrm{~min}$, then blocked and permeabilized with $10 \%$ normal goat serum plus $0.1 \%$ Triton X-100 in PBS for
30 min. Cultures were immunostained with an anti- $\beta$ III-tubulin antibody (1:1000; G7121, Promega), followed, after rinsing with PBS, by an Alexa Fluor 488 goat anti-mouse IgG secondary antibody (1:1000; A11029, Invitrogen). Images were acquired with an ImageXpress Micro imaging system (Molecular Devices) using a 10× objective. Neurite regeneration was analyzed using MetaXpress Version 1.7 software. The central $75 \%$ of the lesion was analyzed by cropping the image and analyzing neurite growth using an angiotube formation algorithm. The area covered by neurites was measured, and all values were normalized to the control. Results were analyzed by one-way ANOVA and Fisher's leastsignificant difference post hoc test.

Microarray studies. We investigated patterns of gene expression in layer 5 pyramidal cells of the forelimb motor area contralateral to the damaged hemisphere in four groups of rats, each containing three to six individual animals. These neurons were selected for study because parts of this population, though not necessarily the individual neurons that were isolated, give rise to the novel projections visualized in the anatomical studies. As before, rats underwent stroke surgery and were implanted with minipumps delivering either saline or inosine into the lateral ventricle of the undamaged hemisphere as described above. All rats used in the microarray study were initially housed individually. After $3 \mathrm{~d}$, half the rats in each treatment group were randomly selected and transferred to the EE boxes described above, while the remainder continued to be housed in isolation. To focus on gene changes associated with the early response to $\mathrm{EE}$, rats were anesthetized and killed by decapitation $4 \mathrm{~d}$ later. Brains were rapidly dissected and cut in the coronal plane to prepare tissue blocks that included the forelimb motor cortex. Blocks were rapidly frozen in OCT Tissue Tek Medium (Sakura Finetek USA) and stored at $-80^{\circ} \mathrm{C}$ until ready for sectioning on a cryostat at $10 \mu \mathrm{m}$. Sections were mounted on slides (Gold Seal RITE-ON glass slides), cooled, and stored at $-80^{\circ} \mathrm{C}$ until ready to use.

Laser-capture microdissection was performed as described previously (Zai et al., 2009). In brief, sections were thawed, dehydrated under RNase-free conditions, and $\geq 500$ layer 5 pyramidal cells in the forelimb motor area of the undamaged hemisphere were captured individually using the Arcturus VERITAS system and stored in Arcturus extraction buffer $\left(-80^{\circ} \mathrm{C}\right)$. We extracted RNA using the Micro-to-Midi TotalRNA Purification System (Invitrogen), then performed two cycles of RNA amplification (TargetAmp 2-Round Aminoallyl-aRNA Amplification kit 1.0, Epicenter Biotechnologies). Microarray hybridization and analysis were performed essentially as described previously (Carmichael et al., 2008; Zai et al., 2009). Briefly, amplified RNA was checked for average fragment length (RNA 6000 Nano LabChip Kit, Agilent Technologies), biotinylated, and hybridized ( $1 \mu \mathrm{g})$ on RatRef-12 Expression BeadChip arrays (Illumina), querying the expression of $>22,000$ RefSeq-curated rat transcripts. Slides were processed and scanned (BeadStation platform, Illumina), and raw data were analyzed using Bioconductor packages as described previously (Gentleman et al., 2004). First-level quality-control analysis was performed using clustering based on variance and by comparing gene expression patterns for individual cases to group means (Pearson correlations) (Oldham et al., 2008). To decrease noise, three cases that showed a relatively low correlation to their respective group means $\left(r^{2}<0.94\right)$ were excluded, increasing the $r^{2}$ values for the remaining cases to $\geq 0.97$. The final analysis included $n=4$ samples from rats treated with saline reared in isolation, $n=4$ treated with inosine and reared in isolation, $n=4$ treated with saline and exposed to EE, and $n=$ 3 treated with inosine and exposed to EE. Data were normalized using quantile normalization, and analysis of differential expression was performed using linear model fitting (LIMMA package) (Smyth et al., 2005). Differentially expressed genes were classified according to gene ontology using Bioconductor packages and online tools (DAVID, http://david. abcc.ncifcrf.gov/). Pathway analysis was performed using Ingenuity Pathway Analysis (Ingenuity Systems).

\section{Results}

Inosine combined with NEP1-40

The first study tested the hypothesis that inosine and NEP1-40, by acting through complementary mechanisms, will lead to greater anatomical reorganization and stronger improvements in perfor- 
mance when combined than in isolation. Failure to confirm this hypothesis would imply that the two treatments act through a common cellular pathway, or that the effects of either one represent an upper limit on corticospinal tract plasticity and/or functional outcome after stroke. Rats were pretrained before surgery to reach for food pellets at a criterion level using each paw. Under stereotaxic guidance, we then used the photothrombotic method of Markgraf et al. (1993) to create unilateral ischemic damage in the caudal forelimb motor area, and immediately began intracranial delivery of inosine or saline, with or without NEP1-40.

\section{Lesion size and localization}

As reported earlier (Zai et al., 2009), infarcts had a diameter of 6-7 mm and were generally restricted to cortical tissue and some underlying white matter. In addition to the forelimb motor area, lesions included varying amounts of adjacent cortex but minimal damage to the underlying basal ganglia (supplemental Fig. 1a, available at www.jneurosci.org as supplemental material). Our prior study (Zai et al., 2009) and another laboratory (Shen et al., 2005) have shown that inosine does not alter lesion size after stroke. The present results show that lesion size was likewise unaffected by NEP1-40, with or without inosine (supplemental Fig. $1 b$, available at www.jneurosci.org as supplemental material).

\section{Combinatorial treatment enhances CST reorganization}

To investigate changes in CST organization, we injected BDA into the uninjured SMC at the completion of behavioral testing, waited 2 weeks for BDA to be transported to the cervical spinal cord, then killed rats and prepared the brains for histology. Sections were examined for axon growth and synapse formation from CST axons that arise from neurons on the undamaged side of the brain and cross over into the denervated side of the spinal cord at the cervical level. One-way ANOVA revealed an overall effect of treatment on CST axon branches that project from the intact hemisphere into the denervated ipsilateral dorsal funiculus $(p<0.05)$, labeled fibers that continue on into the denervated neuropil ( $p<0.001$ ), crossed fibers that extend long distances through the neuropil $(p<0.0001)$, and bouton-like structures that arise from crossed CST axons $(p<0.001)$. Individual comparisons were done using Tukey's post hoc analysis. Inosine and NEP1-40 each induced a threefold increase in the number of $\mathrm{BDA}+$ fibers that projected from the undamaged cortex to the denervated, ipsilateral dorsal funiculus compared with controls treated with saline alone $(p<0.05)$ (Fig. $1 a-d, i)$, and caused a similar increase in the number of CST axon branches $\geq 40 \mu \mathrm{m}$ in the denervated cervical gray matter (Fig. 1j). Both treatments caused a somewhat larger increase in the number of longer fibers $(>200 \mu \mathrm{m}$ in the transverse plane) (Fig. $1 f, g, k)(p<0.05)$ (Zai et al., 2009). As expected, all of these increases covaried. In addition to the main part of the CST, some crossed CST fibers course through the lateral funiculus (Casale et al., 1988; Rouiller et al., 1991), while a relatively small number of uncrossed CST fibers run along the ventral midline of the spinal cord (Brösamle and Schwab, 1997). It is possible that CST axons within these bundles may have contributed to the observed increases in axon growth after treatment.

Inosine combined with NEP 1-40 had considerably stronger effects than either treatment alone. Combined treatment doubled the number of fibers $\geq 40 \mu \mathrm{m}$ in length within the denervated gray matter compared with inosine $(p<0.05)$ or NEP1-40 $(p<$ $0.01)$ alone. This change represents a sixfold increase relative to saline-treated controls (Fig. 1j) $(p<0.001)$. Inosine combined with NEP1-40 likewise doubled the number of lengthy axons $(>200 \mu \mathrm{m})$ relative to inosine or NEP1-40 alone (Fig. 1h,k) $(p<$ 0.05 for both).

Crossed CST axons formed bouton-like structures in the gray matter on the denervated side of the spinal cord. These structures appear as local swellings two times or more the width of the axons (Fig. $1 e-h$ ), and have been shown to correspond to synaptic boutons at the electron microscopic level (Lagerbäck et al., 1981; Havton and Kellerth, 1987). Camera lucida tracings illustrate the shape and size of both en passant and terminal boutons (Fig. $\left.1 e^{\prime}-h^{\prime}\right)$. As expected, the numbers of these swellings were generally proportional to the number of crossed axons. Treatment with either inosine or NEP 1-40 alone nearly tripled the number of bouton-like structures compared with saline (Fig. 1l) $(p<0.05)$; combining the two resulted in nearly five times more boutons than were seen in untreated controls (Fig. 1l) ( $p<0.05$, comparing combined treatment with either treatment alone).

In view of the large effect of the combined treatment on the denervated side of the spinal cord, we investigated whether it might also affect CST organization on the intact side. Because the high density of fibers on the intact side precluded a comprehensive fiber count, we focused on lamina 9, a region in which no CST fibers project ordinarily (Yang and Lemon, 2003). After stroke, this region was nearly devoid of CST input in saline-treated animals, and neither inosine nor NEP1-40 altered this situation. However, combining the two increased the number of fibers entering lamina 9 and overlying ventral motor neurons (supplemental Fig. 2, available at www.jneurosci.org as supplemental material).

\section{Combined therapy restores skilled reaching to near-normal levels}

Functional recovery was evaluated using a reaching test that requires pretraining and involves fine motor control of the forelimbs, forepaws, and digits. Animals were trained to retrieve food pellets with either paw before surgery and both paws were tested afterward. Scores were normalized by rats' preoperative level of performance. As expected, all groups showed a near-complete loss in their ability to retrieve food pellets with the paw contralateral to the stroke in the first week. Two-way ANOVA (repeat measures) revealed highly significant overall effects of treatment and time ( $p<0.0001$ for each). By week 4 , inosine-treated rats were performing at $73 \%$ of their preoperative level, compared with $32 \%$ in saline-treated controls (Fig. 2a) (post hoc analysis using Bonferroni's correction, $p<0.05$ ). Animals treated with NEP1-40 likewise showed an overall superiority to saline-treated controls and performed at $68 \%$ of their preoperative level by week 4 (Fig. 2a) (difference significant at $p<0.05$ ). Combining inosine with NEP1-40 resulted in appreciably better performance than either inosine alone (all $p<0.05$ ) or NEP1-40 alone (all $p<0.01$ ). By week 4 , rats receiving combined treatment were able to retrieve food pellets with the impaired paw at a normal rate (Fig. $2 c, d$ ).

Using the unimpaired paw, animals in all groups showed a small decline in performance at week 1 , perhaps due to difficulty in balancing on the impaired limb, but performed normally from week 2 onward (Fig. 2b). Thus, the deficits observed using the impaired paw cannot be attributed to differences in motivation or overall behavioral competence.

To determine whether the benefits of combined treatment persist, we generated new groups of animals that were treated for 4 weeks after stroke as before but then were tested for an additional 4 weeks after treatments ended. The saline- and inosine-treated animals of this study have been described pre- 

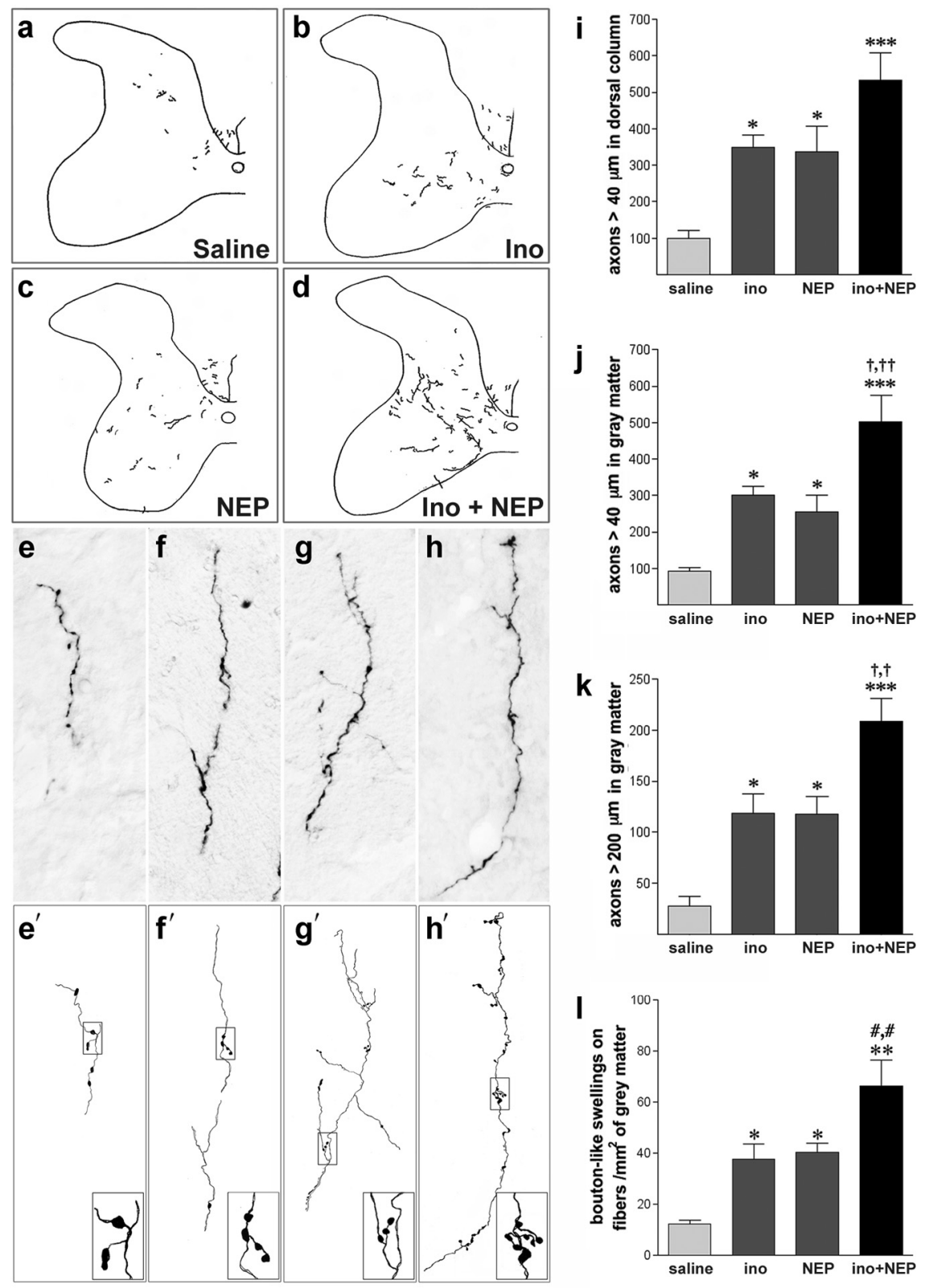

Figure 1. Inosine enhances the effects of NEP1-40 on CST reorganization. $\boldsymbol{a}-\boldsymbol{d}$, Low-power camera lucida drawings of the spinal cord gray matter contralateral to the stroke at the level of the cervical enlargement. Drawings illustrate BDA-labeled CST fibers that originate in the undamaged hemisphere in rats treated with saline $(\boldsymbol{a})$, inosine (ino, $\boldsymbol{b})$, NEP1-40 (NEP, $\boldsymbol{c}$ ), or NEP1-40 plus inosine (d). $\boldsymbol{e}-\boldsymbol{h}$, High-magnification photomicrographs showing some of the longest BDA-labeled fibers in the denervated gray matter of rats treated as in $\boldsymbol{a}$ and $\boldsymbol{d}$, respectively. $\boldsymbol{e}^{\prime}-\boldsymbol{h}^{\prime}$, Camera lucida tracings of the fibers shown in $\boldsymbol{e}-\boldsymbol{h}$. Insets show higher-magnification views of bouton-like structures along axons. $\boldsymbol{i}, \boldsymbol{j}$, Quantitation of BDA-labeled CST fibers $\geq 40 \mu \mathrm{m}$ in length (in the transverse plane) in the denervated dorsal funiculus (i) and gray matter (j). $\boldsymbol{k}, \mathrm{BDA}$-labeled CST fibers as in $\boldsymbol{j}$ but $\geq 200 \mu \mathrm{m}$ in length. $\boldsymbol{I}$, Synaptic bouton-like structures in the denervated gray matter. ${ }^{*} p<$ $0.05,{ }^{* *} p<0.01,{ }^{* * *} p<0.01$, difference from animals with stroke treated with saline; ${ }^{\dagger} p<0.05,{ }^{+\dagger} p<0.01$, difference from animals treated with inosine or NEP1-40 alone. Results in $\boldsymbol{i}-\boldsymbol{I}$ are reported per millimeter of spinal cord. $\boldsymbol{a}$ and $\boldsymbol{b}$ are reproduced from Zai et al. (2009).

viously (Zai et al., 2009). Two-way ANOVA (repeated measures) revealed significant overall effects of treatment and time ( $p<0.0001$ for each). Animals treated with NEP1-40, with or without inosine, continued to improve after the treatments ended. Rats treated with inosine plus NEP1-40 scored considerably better than those treated with NEP1-40 alone from week 5 on (all $p<0.05$, Bonferroni's post hoc test), performing at a level at or above their preoperative baseline
(Fig. 2c). Inosine-treated rats run in parallel to the rats of the present study were previously reported to perform at $\sim 80 \%$ of their preoperative level at week 8 (Zai et al., 2009), and, as shown here, rats treated with inosine + NEP140 were superior to these from week 4 on (all $p<0.05$ ). As expected, animals in all groups continued to perform normally with the paw contralateral to the uninjured hemisphere (Fig. 2d). The results of this study confirm the effects of NEP1-40 combined with inosine seen in the 4 week study and show that the benefits of these treatments persist long after treatment ends. Thus, 4 weeks after suffering extensive cortical damage, rats treated with inosine + NEP1-40 scored as high as normal animals in the skilled reaching task using the impaired forelimb and retained this ability in the absence of further treatment.

\section{Inosine combined with NEP1-40} enhances neurite outgrowth on myelin Previous studies have shown that inosine promotes outgrowth from embryonic cortical neurons on a permissive substrate (Irwin et al., 2006) and that NEP1-40 enables other types of postnatal neurons to extend axons on myelin (GrandPré et al., 2002). Although cortical cultures are most readily prepared from embryonic cortex or early postnatal brain, these neurons express little or no $\mathrm{NgR} 1(\mathrm{NgR} 1)$ at this stage and are therefore of questionable relevance to adult stroke recovery. However, NgR1 expression increases with time in culture and becomes similar to adult brain levels by 3-4 weeks in vitro (data not shown). We therefore used cortical cultures maintained for 21 DIV to study the individual and combined effects of inosine and NEP1-40 on neurite regeneration. Mature cultures were scraped with a multipin tool in 96 well plates to create axonal injuries. Fibers were then allowed to regenerate into the zone cleared of neurites in the presence or absence of myelin for $5 \mathrm{~d}$ (Fig. 3A). As expected, the presence of CNS myelin $(100 \mu \mathrm{g} / \mathrm{ml})$ strongly inhibited regeneration across the scrape zone (Fig. $3 B, C$ ). Inosine at either 0.1 or $1 \mathrm{~mm}$ showed a trend toward increasing outgrowth over myelin, as did NEP1-40 alone. Importantly, combining the two enabled a significant amount of regenerative growth to occur in the presence of myelin, approaching the level of growth seen in the absence of myelin (Fig. 3B,C) (one-way ANOVA, Fisher's least-significant difference test). This study enables us to directly visualize the combined effect of inosine and NEP1-40 in overcoming myelin inhibition. 

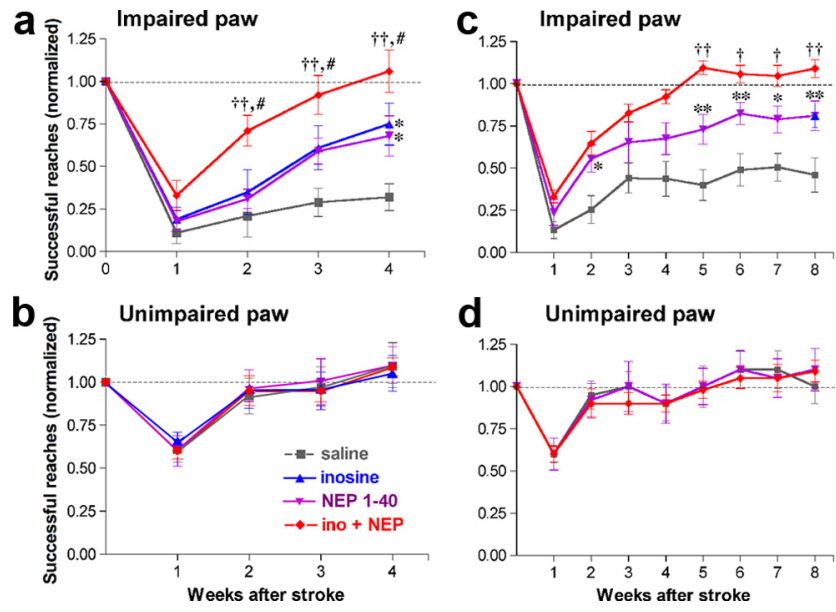

Figure 2. Inosine combined with NEP1-40 restores performance with the impaired paw to preoperative levels. Rats were pretrained to retrieve food pellets through a narrow opening using either paw before stroke surgery, and were tested with either the impaired paw (i.e., contralateral to the stroke) $(\boldsymbol{a}, \boldsymbol{c})$ or the unimpaired paw $(\boldsymbol{b}, \boldsymbol{d})$ for either 4 weeks $(\boldsymbol{a}, \boldsymbol{b})$ or 8 weeks $(\boldsymbol{c}, \boldsymbol{d})$. $\boldsymbol{a}$, Inosine or NEP1-40 each improved recovery using the impaired paw. Combining the two resulted in far stronger recovery and enabled rats to perform at preoperative levels by week 3. $\boldsymbol{b}$, Performance with the unimpaired paw was unaffected by treatment. $\boldsymbol{c}, \boldsymbol{d}$, In a second, independent study, rats were treated with or without inosine and/or NEP1-40 for 4 weeks and tested for another 4 weeks. Animals treated with NEP1-40, with or without inosine, continued to improve after treatment ended. Rats with combined treatment continued to score at normal, preoperative levels after $4-5$ weeks. $\boldsymbol{d}$, Performance with the paw ipsilateral to the stroke is unaffected by treatment. ${ }^{*} p<0.05,{ }^{* *} p<0.01,{ }^{* * *} p<0.001$, difference from saline-treated controls; ${ }^{\dagger} p<0.05,{ }^{+\dagger} p<0.01$, difference from rats treated with NEP1-40; ${ }^{\#} p<0.05,{ }^{\# \#} p<0.01$, difference from rats treated with inosine. Performance was evaluated by a blinded observer. Group means ( \pm SEM) are reported as percentages of preoperative performance. The 8 week performance level of inosine-treated rats from an earlier study (Zai et al., 2009) is shown for reference (blue triangle in c).

\section{Inosine combined with environmental enrichment}

The next set of studies tested the hypothesis that inosine enhances the effects of rearing animals in an enriched environment. Although inosine and EE each improves functional outcome after stroke, it is not known whether EE alters CST organization nor whether the two treatments combined affect outcome to a greater extent than either one alone. This study was initially intended to be independent from the ones described above and differed in several experimental details. Following pretraining and stroke surgery, rats were either reared in pairs or, beginning $3 \mathrm{~d}$ after stroke, were maintained in a complex environment with opportunities for climbing, exploring, and social interactions. Half the animals in each condition received intraventricular infusions of inosine as before, whereas the other half received saline. Treatments ended after 4 weeks, but exposure to EE [or to a standard environment (SE)] and behavioral testing continued for another 4 weeks. Thus, unlike the prior study that involved two independent experiments with 4 and 8 week survival periods, the effects of EE and the persistence of these effects were evaluated in a single 8 week study.

\section{CST reorganization}

As in our prior studies, the distribution of axons originating in the intact forelimb motor area was evaluated by anterograde tracing with BDA after completing the behavioral studies. One-way ANOVA revealed a significant overall effect of treatment $(p<$ $0.0001)$. In rats maintained in an SE, inosine increased the number of CST axon branches that projected from the undamaged hemisphere to the denervated side of the spinal cord fivefold compared with saline-treated controls (Fig. 4a) $(p<0.001$, Tukey's post hoc correction). This increase is greater than that seen in the previous study (Fig. $1 j$ ), reflecting a combination of somewhat more growth in rats treated with inosine in the present series compared with the previous study, and relatively less growth in rats treated with saline. Conceivably, these differences could arise from the longer survival times used here (i.e., 8 vs 4 weeks), but this has not been studied systematically. EE also increased CST sprouting $(p<0.05)$ (Fig. $4 a)$ though to a lesser degree than inosine. Contrary to our expectations, inosine combined with EE produced no more sprouting than inosine alone (Fig. 4a).

\section{Behavioral outcome}

As expected from the first set of experiments and our prior studies (Zai et al., 2009), inosine improved animals' ability to retrieve food pellets with the impaired forepaw. Two-way ANOVA (repeated measures) revealed significant overall effects of treatment and time ( $p<0.0001$ for each). Controls housed in SE conditions after stroke and treated with saline reached a plateau of $\sim 45 \%$ of their preoperative level of performance after 4 weeks (Fig. $4 b$ ), comparable to the level seen in saline-treated controls in the 8 week study (Fig. 2c), but somewhat higher than in the 4 week study (Fig. 2a). Inosine, in comparison, enabled rats to attain $\geq 80 \%$ of their preoperative success rate by week 7 ( $p<0.05$ for inosine vs saline-treated animals at weeks 5,7 , and 8 ). EE enabled rats to retrieve food pellets at a level intermediate between that of inosine- and saline-treated rats reared in SE. Animals treated with inosine and exposed to EE performed better than all other groups from the fourth week on and continued to improve after treatment ended $[p<0.05$ compared with saline-treated controls exposed to SE from week 2 onward; $p<0.05$ compared with saline-treated animals exposed to EE at weeks 7-8 (post hoc analyses using Bonferroni's correction)]. By week 7, inosine-treated animals exposed to EE were able to retrieve food pellets at their preoperative levels (Fig. 4b). Using the forelimb contralateral to the intact hemisphere, scores remained normal for all groups after the first week (Fig. 4c).

\section{Gene expression}

To maximize our chances of detecting an effect of environment on gene expression, rats were reared in isolation for $3 \mathrm{~d}$ after stroke and were either maintained in this condition or exposed to EE for the next $4 \mathrm{~d}$. At the end of this period, we isolated layer 5 pyramidal cells of the intact hemisphere by laser capture microdissection and analyzed gene expression using microarrays. Although animals did not evidence an overt behavioral response to EE after $4 \mathrm{~d}$, we hypothesized that a neuronal response would be taking place at this time point.

Analysis of the microarray results revealed a striking interaction between inosine and EE. For animals reared in isolation for a week, inosine barely affected gene expression. This finding can be visualized by the close correlation between the expression levels of individual genes seen in animals treated with inosine after stroke and reared in SE versus those treated with saline under the same rearing conditions $\left(R^{2}=0.98\right)$ (Fig. $\left.5 a\right)$. Using as criteria that changes be significant at $p \leq 0.01, \geq 1.7$-fold in magnitude, and that at least one signal is $\geq 22^{7}$, inosine altered the expression of only 21 genes relative to saline-treated controls (16 increases and 5 decreases) (supplemental Table 2a, available at www. jneurosci.org as supplemental material). One of the increases associated with inosine was Slpi (secretory leukocyte protease inhibitor), a protein that enhances the ability of axons to grow 

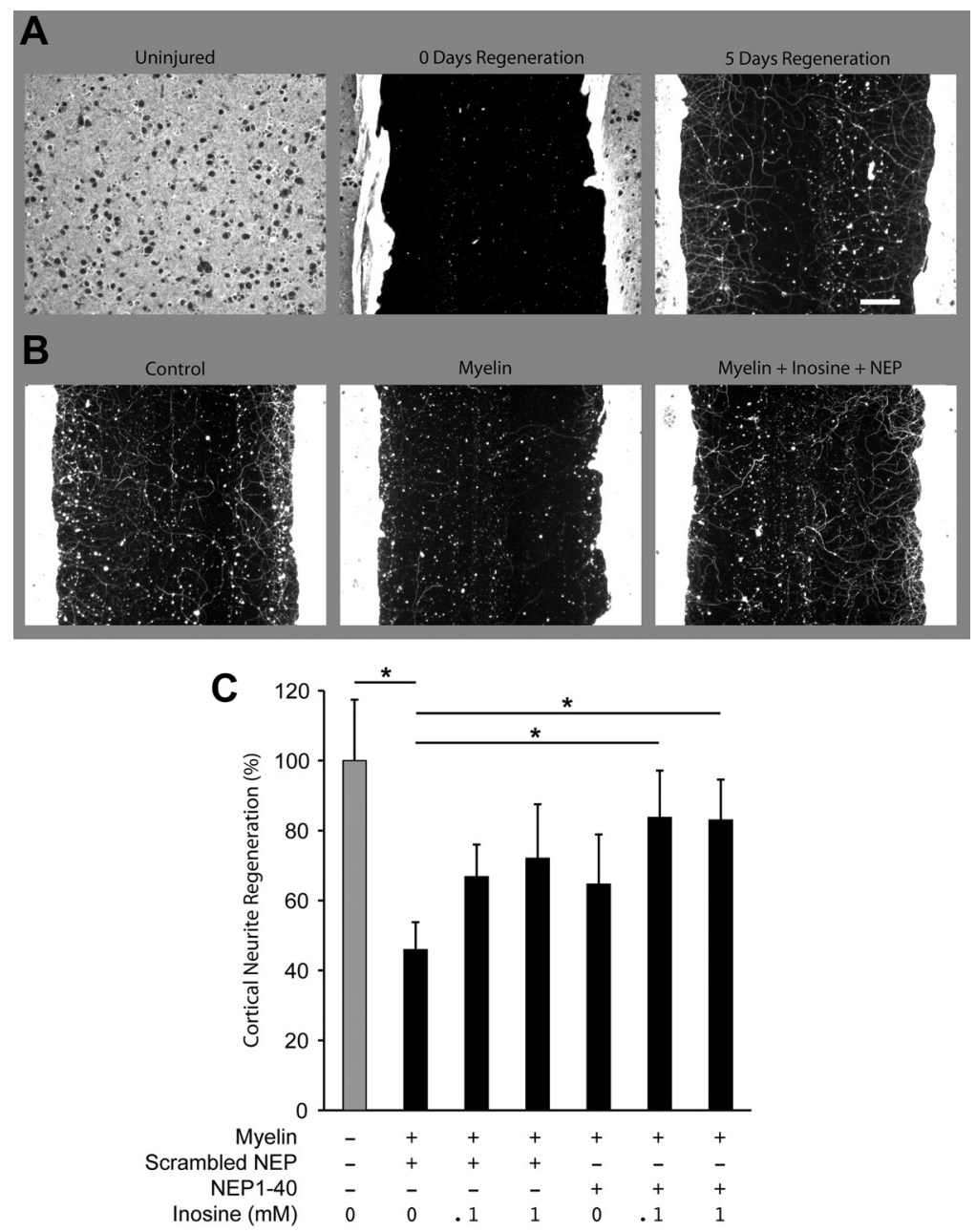

Figure 3. Cortical neurite regeneration. $\boldsymbol{A}$, After 21 DIV, dissociated E18 cortical neurons have created a dense network of anti- $\beta$ III tubulin immunoreactive processes. A scrape injury clears all of these neurites from a 500 - $\mu \mathrm{m}$-wide zone, and regenerative growth occurs over a $5 \mathrm{~d}$ period. $\boldsymbol{B}$, Representative photomicrographs of neurite regeneration in cortical cultures $s c r a p e d$ at 21 DIV. Regeneration proceeded for $5 \mathrm{~d}$ in the absence of inhibitor, or in the presence of $100 \mu \mathrm{g} / \mathrm{ml}$ myelin with or without inosine $(0.1$ or $1 \mathrm{~mm}$ ) and/or NEP1-40, as indicated. Cultures were immunostained for $\beta$ Ill-tubulin to visualize regenerated neurites. C, Quantitation of neurite regeneration. Myelin inhibited regeneration, and this inhibition was significantly attenuated by the combination of inosine and NEP $1-40\left(^{*} p<0.05\right)$. Data show means $\pm \mathrm{SEM} ; N=8$ wells per condition. Scale bar, $100 \mu \mathrm{m}$.

over inhibitory substrates (Hannila and Filbin, 2008). Two of the five decreases were for per genes, which are involved in circadian regulation. Using less stringent criteria (changes significant at $p<0.01$, magnitude of the changes unconstrained), gene networks affected by inosine when animals were reared in isolation included "gene expression, connective tissue development and function and tissue morphology" [ 14 of 34 genes, Ingenuity Pathway Analysis (IPA)], "cell-to-cell signaling and interaction" (14 of 41 genes, IPA), inflammatory response/cellular movement (13 of 35 genes, IPA), and cellular growth/inflammatory response (6 of 34 genes, IPA). These effects overlapped slightly with canonical pathways involved in regulating circadian rhythm [3 of 33 genes, $p \sim 0.0025$ and CD27 signaling in lymphocytes ( 3 of 56 genes, $p \sim 0.01$, IPA).

In contrast to the above results, inosine had a stronger effect on gene expression when rats were exposed to EE. The correlation between gene expression levels in animals treated with inosine after stroke versus saline declined significantly when rats were reared in EE rather than SE (Fig. $5 b)\left(R^{2}=0.95 ; z\right.$ value for difference in $R^{2}$ values $\left.=38.72, p<0.0001\right)$. Under EE condi- tions, inosine treatment increased the expression of 68 genes $\geq 1.7$-fold and decreased the expression of 52 genes $\leq 1$-/1.7-fold ( $p<0.01$; at least one signal $\geq 128$ ) (supplemental Table $2 b$, available at www.jneurosci.org as supplemental material). Using a criterion of $p<0.01$ without specifying the magnitude of the changes, principal networks affected by inosine were "neurological disease, cellular function and maintenance, cellular assembly and organization" (14 of 35 genes, IPA), "cell cycle, cellular development, cellular growth and proliferation (13 of 35 genes, IPA), "cell morphology, endocrine system disorders, cardiovascular system development and function" (13 of 35 genes, IPA), "gene expression, cellular growth and proliferation, cellular development" (12 of 35 genes, IPA), and "inflammatory response, inflammatory disease, cell death" (12 of 35 genes, IPA). These changes did not overlap strongly with any particular canonical pathways.

An alternative way to analyze these results is by examining the effect of varying environmental rearing conditions when rats were treated with inosine or saline. EE had little effect when rats were treated with saline, increasing the expression of only one gene (Gfra2, the neurturin receptor) $>1.7$-fold compared with animals reared in isolation, and decreasing the expression of 28 genes by $\leq 1 / 1.7$-fold ( $p<$ 0.01 , at least one signal $\geq 128$ ) (supplemental Table 2c, available at www. jneurosci.org as supplemental material). Accordingly, gene expression levels in layer 5 pyramidal cells were highly correlated between rats exposed to EE versus rats reared in isolation $\left(R^{2}=0.97\right)$ (Fig. $5 c$ ). Using the criterion of $p<0.01$ without constraining the magnitude of the changes, affected networks included "lipid metabolism, molecular transport and small molecule biochemistry" (13 of 35 genes, IPA), and "developmental disorders, cellular growth and proliferation, and tissue morphology" (10 of 35 genes, IPA). We did not observe effects on a large percentage of genes in any particular canonical pathway.

Inosine treatment alters the effects of $\mathrm{EE}$ on gene expression In the presence of inosine, EE increased the expression of 247 genes $\geq 1.7$-fold, while decreasing the expression of 227 genes $\leq 1 / 1.7$-fold (compared with inosine-treated rats reared in isolation) (supplemental Table 2d, available at www.jneurosci.org as supplemental material). Correspondingly, the correlation between levels of gene expression in rats reared under EE conditions versus isolation declined markedly when rats were treated with inosine $\left(R^{2}=0.91\right)$ (Fig. $\left.5 d\right)$ compared with saline $(z=35.4, p<$ $0.0001)$. In the presence of inosine, $\mathrm{EE}$ affected a high percentage of genes in several networks, particularly those involved in "cell signaling, cellular function and maintenance, and molecular transport" (28 of 35 genes, IPA), "cellular response to therapeutics, cellular assembly and organization, DNA replication, re- 
a

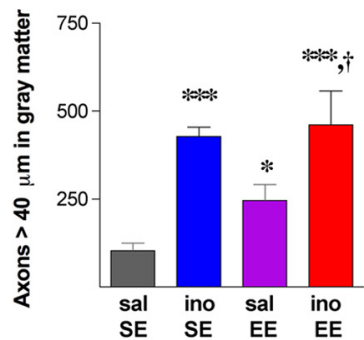

b

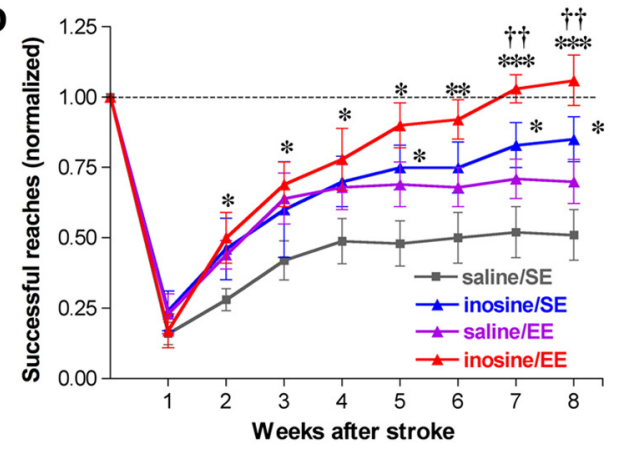

C

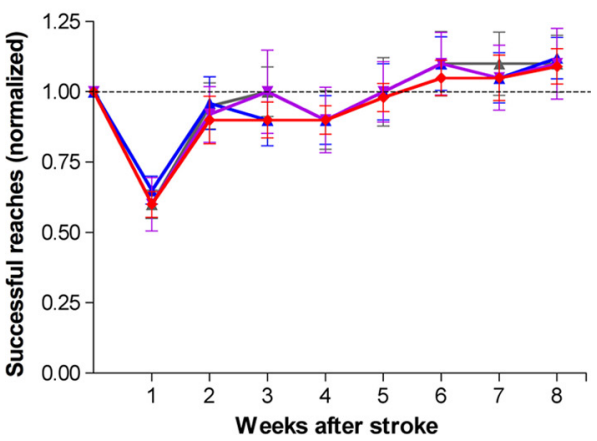

Figure 4. Inosine enhances the behavioral effects of EE. $\boldsymbol{a}$, CST reorganization: axon collaterals arising in the intact hemisphere and projecting to the ipsilateral (denervated) cervical spinal cord. $\boldsymbol{b}, \boldsymbol{c}$, Time course of functional recovery using the impaired paw (i.e., contralateral to the stroke) (b) or the unimpaired paw (c). Animals were maintained in either complete isolation or exposed to EE beginning on day 3, and were treated with saline or inosine for 4 weeks. Testing was performed weekly from weeks 1 through 8 . Inosine-treated animals exposed to EE returned to prestroke levels of competence by week 7. ${ }^{*} p<0.05,{ }^{* *} p<0.01$, ${ }^{* * *} p<0.001$, difference from saline-treated controls; ${ }^{\mathrm{t}} p<0.05,{ }^{\mathrm{t}} p<0.01,{ }^{\mathrm{Ht}} p<0.001$, difference from inosine-treated animals reared in SE; ${ }^{\#} p<0.05,{ }^{\#} p<0.01,{ }^{\# \#} p<0.001$, difference from saline-treated rats exposed to EE.

combination and repair" (28 of 35 genes, IPA), "developmental disorder, genetic disorder, reproductive system disease" (28 of 35 genes, IPA), "cell death, cell cycle, cellular growth and proliferation" (18 of 35 genes, IPA), "cell-to-cell signaling and interaction, nervous system development and function, cell morphology" (16 of 34 genes). These effects did not overlap strongly with any particular canonical pathways, but included some genes involved in "hypoxia in the cardiovascular system" ( 10 of 70 genes, $p<0.001$, IPA), "Huntington's disease" (19 of 234 genes, $p<0.01$, IPA), and "DNA methylation and transcriptional repression" (2 of 23 genes, $p \sim 0.01$, IPA).

These results show that inosine and EE interact strongly with one another to alter gene expression after stroke. In rats reared in isolation, inosine barely affected gene expression in layer 5 pyramidal cells of the forelimb motor area contralateral to the stroke. Similarly, when rats were treated with saline, EE had little effect on gene expression. However, in the presence of inosine, EE profoundly altered gene expression. A heat map of these results (Fig. $5 e$ ) shows the intragroup similarities in patterns of gene expression and the strong effect of combinatorial treatment. The mo-
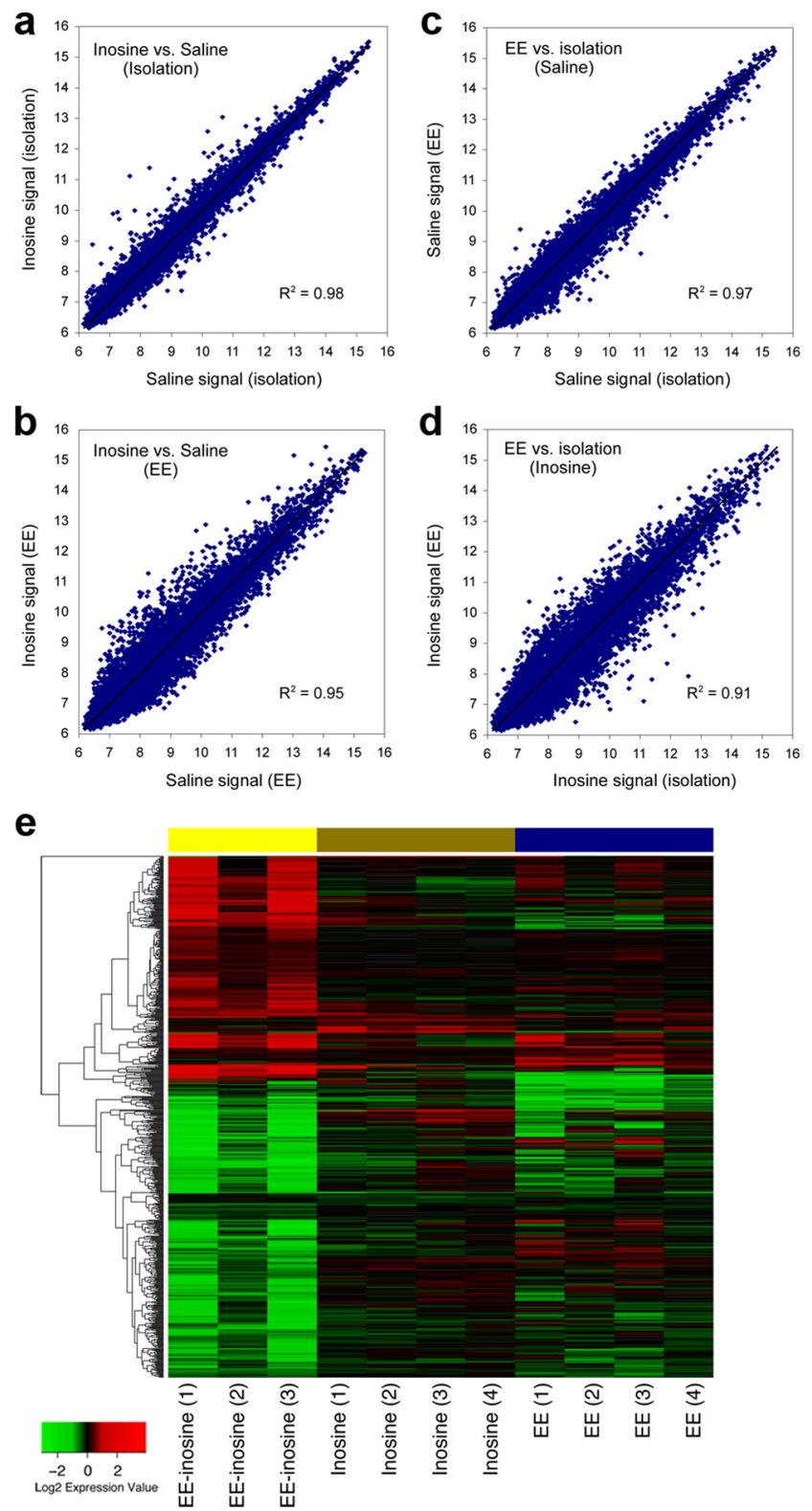

Figure 5. Inosine and EE synergistically alter gene expression in layer 5 pyramidal cells of the undamaged hemisphere. $\boldsymbol{a}$ - $\boldsymbol{d}$, Scatter diagrams show normalized, $\log _{2}$-transformed levels of gene expression in animals treated with saline or inosine after stroke and either reared in isolation or exposed to EE. $\boldsymbol{a}, \boldsymbol{b}$, Effect of rearing conditions. Inosine did not markedly alter the pattern of gene expression compared with saline-treated animals when rats were reared in isolation, as indicated by the low level of scatter from the trend line and the high correlation coefficient $(\boldsymbol{a}) . \boldsymbol{b}$, Inosine induced many changes in gene expression when animals were exposed to EE. $\boldsymbol{c} \boldsymbol{d}$, Effect of inosine. When rats were treated with saline, EE did not markedly alter the pattern of gene expression compared with rats reared in isolation (c). However, in rats treated with inosine, $\mathrm{EE}$ caused massive changes in gene expression, as seen by the low correlation in signal strength between samples. $\boldsymbol{e}$, Heat map representing the top differentially expressed genes. Gene changes are shown for three comparisons: inosine versus saline in standard environment (inosine effect); enriched versus standard environment in animals treated with saline (EE effect); and combined effect of inosine and EE versus saline-treated animals reared in SE. Each individual treatment shows a limited number of changes, whereas the combined treatment induces a larger set of changes. Samples are in columns, genes are in rows, clustered by similarity. Red cells represent upregulated genes, green cells, downregulated genes. Represented here are all the probes with a $p$ value $<0.005$ for any of the three comparisons.

lecular changes observed when rats were treated with inosine and exposed to EE mirror the synergistic effects of the two treatments on behavioral outcome, providing a molecular correlate of this phenomenon and a foundation for investigating the complex mechanisms involved. 


\section{Discussion}

Inosine diffuses across the cell membrane and activates the protein kinase Mst3b, a key part of the signal transduction pathway through which growth factors induce neurons to extend axons (Irwin et al., 2006; Lorber et al., 2009). Our results confirm earlier studies showing that inosine exerts a strong effect on axonal reorganization and functional outcome after stroke, while demonstrating for the first time that it enhances the effects of treatments that promote growth through complementary mechanisms. When combined with either a peptide antagonist to the Nogo receptor or environmental enrichment, inosine enabled rats with cortical strokes to reach through a restricted opening and retrieve food pellets with their impaired forelimbs at the same rate as normal animals.

\section{Inosine enhances the effects NEP1-40}

Three myelin-associated proteins, Nogo-A, myelin-associated glycoprotein (MAG), and oligodendrocyte-myelin glycoprotein, suppress axon growth via NgR (Fournier et al., 2001; Filbin, 2003; Liu et al., 2006) and other receptors (Atwal et al., 2008; Goh et al., 2008; Hu and Strittmatter, 2008). Following unilateral stroke in rats, agents that block Nogo or NgR enhance the growth of CST axon branches from the undamaged hemisphere into the denervated side of the spinal cord and improve use of the impaired forepaw. These effects can be seen using a recombinant soluble form of $\mathrm{NgR}$, an anti-Nogo antibody, or by deleting the gene for NogoA/B or NgR (Papadopoulos et al., 2002; Lee et al., 2004; Cafferty and Strittmatter, 2006; Tsai et al., 2007). A recent study has shown that NEP1-40, the NgR antagonist used in this study, improves outcome after stroke, but did not investigate anatomical changes (Fang et al., 2010). NEP1-40 was previously shown to promote axon regeneration and improve outcome after spinal cord injury (GrandPré et al., 2002; Li and Strittmatter, 2003; Cao et al., 2008), though one group reported only weak effects in that model and found similar effects using a scrambled version of NEP1-40 (Steward et al., 2008). In the present study, NEP1-40 tripled the number of axon branches projecting from the intact CST to the denervated side of the spinal cord and improved use of the impaired forelimb. Preliminary studies from our laboratory show that a scrambled version of NEP1-40, while not enhancing axon growth over myelin in cell culture, may improve functional outcome after stroke. This effect may be related to an unanticipated resemblance between the scrambled peptide and a portion of MAG (supplemental Fig. 3, available at www.jneurosci.org as supplemental material), enabling it to function in a fashion analogous to NEP1-40.

When combined with NEP1-40, inosine induced nearly twice as much CST sprouting on the denervated side of the spinal cord as either treatment alone, and enabled rats to retrieve food pellets with the impaired forepaw at the same level seen in normal animals. This high level of performance persisted for at least a month after treatment ended, suggesting that, once formed, circuits that sustain behavioral improvements do not require continued application of plasticity-inducing agents. At the same time, the normal performance observed with the impaired paw suggests that the formation of new circuitry for ipsilateral motor control does not strongly compromise the ability of the intact hemisphere to control the contralateral paw. Although we have focused on the CST, in view of its role in the task used here (Raineteau et al., 2001; Anderson et al., 2005; Piecharka et al., 2005) and the relative ease in detecting newly formed ipsilateral projections, the exact relationship between the observed anatomical changes and the behavioral improvements is not known. Changes not inves- tigated in this study may have also played a role in recovery, including possible novel inputs to the forelimb motor area of the undamaged hemisphere and to intact areas in the injured hemisphere (see, e.g., Li et al.; Carmichael et al., 2001; Frost et al., 2003; Dancause et al., 2005; Brown et al., 2008, 2009); descending pathways from spared areas of the injured hemisphere (Bareyre et al., 2004); and/or changes in the efficacy of existing synapses. It is clear that vicariation, the assumption of function by brain areas that did not previously mediate control of the impaired forepaw, occurs in rodent models of stroke even without further treatment (see Introduction), and inosine is likely to have enhanced this process. Establishing the significance of any brain changes to behavioral improvements may require lesions of candidate regions, transections of specific pathways, or agents that prevent the changes from occurring in the first place. We should also note that the present study quantified food retrieval as an endpoint but did not analyze the precise digit and limb movements underlying recovery. Other research in the field would suggest that the functional improvements commonly involve the use of compensatory strategies rather than recovery of the normal pattern of paw use (Whishaw et al., 1991). An additional point is that buprenorphine, which was used throughout as an analgesic, has antiinflammatory effects (Volker et al., 2000) that may affect axonal sprouting in positive or negative ways (Yin et al., 2003; Steinmetz et al., 2005; Gensel et al., 2009; Stirling et al., 2009) and alter patterns of gene expression in the microarray studies.

\section{Inosine enhances the effects of environmental enrichment}

The organization of synaptic connections is shaped by patterns of physiological activity during development, and, to some extent, this process continues later in life (Merzenich and Sameshima, 1993; Darian-Smith and Gilbert, 1994; Katz and Shatz, 1996; Maier et al., 2008). Environmental enrichment, with opportunities for exploring novel objects, climbing, and social interactions, promotes the expression of trophic factors and certain transmitters and increases dendritic arborization, synaptogenesis, gliogenesis, neurogenesis, angiogenesis, and brain thickness (Diamond et al., 1976; Kleim et al., 1998; Klintsova and Greenough, 1999; Rampon et al., 2000; van Praag et al., 2000; Garcia et al., 2003; Ziv et al., 2006). EE exerts many of these same effects plus additional ones after brain injury and leads to improvements in learning, memory, and motor performance (Kolb and Gibb, 1991; Ohlsson and Johansson, 1995; Johansson et al., 1996; Jones et al., 1999; Biernaskie and Corbett, 2001; Farrell et al., 2001; Johansson and Belichenko, 2002; Dahlqvist et al., 2004; Johansson, 2004; Nithianantharajah and Hannan, 2006; Ziv et al., 2006). $\mathrm{EE}$ has also been shown to improve performance on associative learning tests in an animal model of cortical neurodegeneration, mediated via epigenetic changes related to histone acetylation and methylation (Fischer et al., 2007). Thus, some of the beneficial effects of EE may be linked to widespread changes in gene expression.

The present results show that EE promotes CST axon sprouting from the intact side of the brain into the denervated side of the spinal cord after stroke and improves skilled reaching with the impaired forepaw. Inosine augmented the behavioral effects of EE, enabling rats to regain use of the impaired paw after a few weeks. The combination of the two treatments did not enhance CST reorganization beyond the level seen with inosine alone, but markedly altered gene expression in layer 5 pyramidal cells of the undamaged hemisphere. Compared with rats exposed to a standard environment, rats treated with inosine and exposed to EE showed changes in the expression of genes involved in cell signal- 
ing, cell morphology, cell growth, cell maintenance, assembly and organization; DNA replication, recombination and repair; and nervous system development and function. These observations may be linked to the previously noted effects of EE on chromatin remodeling (Fischer et al., 2007). That study and the present one suggest that, whereas rearing in isolation diminishes the overall level of neuronal gene transcription, EE, by fostering histone acetylation and DNA methylation, reverses this situation and enables inosine to influence gene transcription. From another perspective, the ability of EE to affect gene transcription was found to be augmented by inosine. The basis for this observation is unknown. However, our results suggest the possibility that chromatin remodeling and genome-wide transcriptional changes may depend on Mst3b activation, a hypothesis that will require further testing. It might be noted that the molecular changes associated with inosine in the present study do not overlap strongly with those observed previously (Zai et al., 2009), which may be due in part to differences in environmental rearing conditions in the two studies. Whereas rats in the prior study were housed two per cage, rats in the present microarray studies were either reared alone and offered almost no stimulation, or exposed to a great deal of stimulation (EE). Our results show that such differences can profoundly influence gene expression. At a behavioral level, combining NEP1-40 with training that includes many of the features of EE used in this study was recently shown to result in near-complete restoration of skilled motor performance with the impaired limb in mice (Fang et al., 2010). Finally, although the changes in gene expression correlate with behavioral improvements, we do not know which, if any, of the molecular changes enhances the ability of neurons to modify synaptic relationships in an adaptive fashion or promote axon branching. Further analysis of this relationship will require manipulations of candidate genes or their protein products.

In addition to promoting axon rewiring, inosine suppresses the response of cortical neurons to glutamate (Shen et al., 2005), enhances inhibition via benzodiazepine receptors (Marangos et al., 1981), limits the production of inflammatory cytokines (Haskó et al., 2000, 2004), and attenuates hypoxia-induced astrocyte death (Haun et al., 1996; Jurkowitz et al., 1998). Uric acid, a metabolite of inosine, prevents peroxynitrite-induced protein damage, protects the blood-brain barrier, and has potent anti-inflammatory effects (Scott et al., 2002, 2005). Inosine is in use for cardiac patients (Czarnecki et al., 1992), is often taken orally by athletes (Starling et al., 1996), and is in clinical trials for Parkinson's disease (http:// clinicaltrials.gov/ct2/show/NCT00833690). Moreover, studies using radioactive tracers suggest that inosine crosses the bloodbrain barrier efficiently (Nakagawa and Guroff, 1973). Together, these features potentially make inosine a good candidate for enhancing brain rewiring and improving outcome after stroke in patients.

\section{References}

Allred RP, Jones TA (2004) Unilateral ischemic sensorimotor cortical damage in female rats: forelimb behavioral effects and dendritic structural plasticity in the contralateral homotopic cortex. Exp Neurol 190:433-445.

Anderson KD, Gunawan A, Steward O (2005) Quantitative assessment of forelimb motor function after cervical spinal cord injury in rats: relationship to the corticospinal tract. Exp Neurol 194:161-174.

Atwal JK, Pinkston-Gosse J, Syken J, Stawicki S, Wu Y, Shatz C, TessierLavigne M (2008) PirB is a functional receptor for myelin inhibitors of axonal regeneration. Science 322:967-970.

Bareyre FM, Kerschensteiner M, Raineteau O, Mettenleiter TC, Weinmann O, Schwab ME (2004) The injured spinal cord spontaneously forms a new intraspinal circuit in adult rats. Nat Neurosci 7:269-277.
Benowitz LI, Carmichael ST (2010) Promoting axonal rewiring to improve outcome after stroke. Neurobiol Dis 37:259-266.

Biernaskie J, Corbett D (2001) Enriched rehabilitative training promotes improved forelimb motor function and enhanced dendritic growth after focal ischemic injury. J Neurosci 21:5272-5280.

Brösamle C, Schwab ME (1997) Cells of origin, course, and termination patterns of the ventral, uncrossed component of the mature rat corticospinal tract. J Comp Neurol 386:293-303.

Brown CE, Wong C, Murphy TH (2008) Rapid morphologic plasticity of periinfarct dendritic spines after focal ischemic stroke. Stroke 39:1286-1291.

Brown CE, Aminoltejari K, Erb H, Winship IR, Murphy TH (2009) In vivo voltage-sensitive dye imaging in adult mice reveals that somatosensory maps lost to stroke are replaced over weeks by new structural and functional circuits with prolonged modes of activation within both the periinfarct zone and distant sites. J Neurosci 29:1719-1734.

Cafferty WB, Strittmatter SM (2006) The Nogo-Nogo receptor pathway limits a spectrum of adult CNS axonal growth. J Neurosci 26:12242-12250.

Cafferty WB, Duffy P, Huebner E, Strittmatter SM (2010) MAG and OMgp synergize with Nogo-A to restrict axonal growth and neurological recovery after spinal cord trauma. J Neurosci 30:6825-6837.

Cao Y, Shumsky JS, Sabol MA, Kushner RA, Strittmatter S, Hamers FP, Lee DH, Rabacchi SA, Murray M (2008) Nogo-66 receptor antagonist peptide (NEP1-40) administration promotes functional recovery and axonal growth after lateral funiculus injury in the adult rat. Neurorehabil Neural Repair 22:262-278.

Carmichael ST (2003) Plasticity of cortical projections after stroke. Neuroscientist 9:64-75.

Carmichael ST, Wei L, Rovainen CM, Woolsey TA (2001) New patterns of intracortical projections after focal cortical stroke. Neurobiol Dis 8:910-922.

Carmichael ST, Vespa PM, Saver JL, Coppola G, Geschwind DH, Starkman S, Miller CM, Kidwell CS, Liebeskind DS, Martin NA (2008) Genomic profiles of damage and protection in human intracerebral hemorrhage. J Cereb Blood Flow Metab 28:1860-1875.

Casale EJ, Light AR, Rustioni A (1988) Direct projection of the corticospinal tract to the superficial laminae of the spinal cord in the rat. J Comp Neurol 278:275-286.

Chen P, Goldberg DE, Kolb B, Lanser M, Benowitz LI (2002) Inosine induces axonal rewiring and improves behavioral outcome after stroke. Proc Natl Acad Sci U S A 99:9031-9036.

Conner JM, Chiba AA, Tuszynski MH (2005) The basal forebrain cholinergic system is essential for cortical plasticity and functional recovery following brain injury. Neuron 46:173-179.

Cramer SC (2008a) Repairing the human brain after stroke: I. Mechanisms of spontaneous recovery. Ann Neurol 63:272-287.

Cramer SC (2008b) Repairing the human brain after stroke. II. Restorative therapies. Ann Neurol 63:549-560.

Cramer SC, Crafton KR (2006) Somatotopy and movement representation sites following cortical stroke. Exp Brain Res 168:25-32.

Czarnecki W, Mathison R, Harmsen E, Tyberg JV (1992) Inosine-a natural modulator of contractility and myocardial blood flow in the ischemic heart? Am Heart J 124:1446-1459.

Dahlqvist P, Rönnbäck A, Bergström SA, Söderström I, Olsson T (2004) Environmental enrichment reverses learning impairment in the Morris water maze after focal cerebral ischemia in rats. Eur J Neurosci 19:2288-2298.

Dancause N, Barbay S, Frost SB, Plautz EJ, Chen D, Zoubina EV, Stowe AM, Nudo RJ (2005) Extensive cortical rewiring after brain injury. J Neurosci 25:10167-10179.

Darian-Smith C, Gilbert CD (1994) Axonal sprouting accompanies functional reorganization in adult cat striate cortex. Nature 368:737-740.

Diamond MC, Ingham CA, Johnson RE, Bennett EL, Rosenzweig MR (1976) Effects of environment on morphology of rat cerebral cortex and hippocampus. J Neurobiol 7:75-85.

Dijkhuizen RM, Singhal AB, Mandeville JB, Wu O, Halpern EF, Finklestein SP, Rosen BR, Lo EH (2003) Correlation between brain reorganization, ischemic damage, and neurologic status after transient focal cerebral ischemia in rats: a functional magnetic resonance imaging study. J Neurosci 23:510-517.

Dobkin BH (2003) The clinical science of neurologic rehabilitation, Ed 2. New York: Oxford UP.

Fang PC, Barbay S, Plautz EJ, Hoover E, Strittmatter SM, Nudo RJ (2010) 
Combination of NEP 1-40 treatment and motor training enhances behavioral recovery after a focal cortical infarct in rats. Stroke 41:544-549.

Farrell R, Evans S, Corbett D (2001) Environmental enrichment enhances recovery of function but exacerbates ischemic cell death. Neuroscience 107:585-592.

Filbin MT (2003) Myelin-associated inhibitors of axonal regeneration in the adult mammalian CNS. Nat Rev Neurosci 4:703-713.

Fischer A, Sananbenesi F, Wang X, Dobbin M, Tsai LH (2007) Recovery of learning and memory is associated with chromatin remodelling. Nature 447:178-182.

Fournier AE, GrandPre T, Strittmatter SM (2001) Identification of a receptor mediating Nogo-66 inhibition of axonal regeneration. Nature 409:341-346.

Frost SB, Barbay S, Friel KM, Plautz EJ, Nudo RJ (2003) Reorganization of remote cortical regions after ischemic brain injury: a potential substrate for stroke recovery. J Neurophysiol 89:3205-3214.

Garcia C, Chen MJ, Garza AA, Cotman CW, Russo-Neustadt A (2003) The influence of specific noradrenergic and serotonergic lesions on the expression of hippocampal brain-derived neurotrophic factor transcripts following voluntary physical activity. Neuroscience 119:721-732.

Gensel JC, Nakamura S, Guan Z, van Rooijen N, Ankeny DP, Popovich PG (2009) Macrophages promote axon regeneration with concurrent neurotoxicity. J Neurosci 29:3956-3968.

Gentleman RC, Carey VJ, Bates DM, Bolstad B, Dettling M, Dudoit S, Ellis B, Gautier L, Ge Y, Gentry J, Hornik K, Hothorn T, Huber W, Iacus S, Irizarry R, Leisch F, Li C, Maechler M, Rossini AJ, Sawitzki G, et al (2004) Bioconductor: open software development for computational biology and bioinformatics. Genome Biol 5:R80.

Goh EL, Young JK, Kuwako K, Tessier-Lavigne M, He Z, Griffin JW, Ming GL (2008) betal-integrin mediates myelin-associated glycoprotein signaling in neuronal growth cones. Mol Brain 1:10.

GrandPré T, Li S, Strittmatter SM (2002) Nogo-66 receptor antagonist peptide promotes axonal regeneration. Nature 417:547-551.

Hannila S, Filbin M (2008) The role of secretory leukocyte protease inhibitor in the conditioning lesion effect. Presentation 2819/C34. 2008 Neuroscience Meeting Planner. Washington, DC: Society for Neuroscience, 2008. Online.

Haskó G, Kuhel DG, Németh ZH, Mabley JG, Stachlewitz RF, Virág L, Lohinai Z, Southan GJ, Salzman AL, Szabó C (2000) Inosine inhibits inflammatory cytokine production by a posttranscriptional mechanism and protects against endotoxin-induced shock. J Immunol 164:1013-1019.

Haskó G, Sitkovsky MV, Szabó C (2004) Immunomodulatory and neuroprotective effects of inosine. Trends Pharmacol Sci 25:152-157.

Haun SE, Segeleon JE, Trapp VL, Clotz MA, Horrocks LA (1996) Inosine mediates the protective effect of adenosine in rat astrocyte cultures subjected to combined glucose-oxygen deprivation. J Neurochem 67:2051-2059.

Havton L, Kellerth JO (1987) Regeneration by supernumerary axons with synaptic terminals in spinal motoneurons of cats. Nature 325:711-714.

Hu F, Strittmatter SM (2008) The N-terminal domain of Nogo-A inhibits cell adhesion and axonal outgrowth by an integrin-specific mechanism. J Neurosci 28:1262-1269.

Humm JL, Kozlowski DA, Bland ST, James DC, Schallert T (1999) Usedependent exaggeration of brain injury: is glutamate involved? Exp Neurol 157:349-358.

Irwin N, Li YM, O’Toole JE, Benowitz LI (2006) Mst3b, a purine-sensitive Ste20-like protein kinase, regulates axon outgrowth. Proc Natl Acad Sci U S A 103:18320-18325.

Johansson BB (2004) Functional and cellular effects of environmental enrichment after experimental brain infarcts. Restor Neurol Neurosci 22:163-174.

Johansson BB, Belichenko PV (2002) Neuronal plasticity and dendritic spines: effect of environmental enrichment on intact and postischemic rat brain. J Cereb Blood Flow Metab 22:89-96.

Johansson BB, Ohlsson AL (1996) Environment, social interaction, and physical activity as determinants of functional outcome after cerebral infarction in the rat. Exp Neurol 139:322-327.

Jones TA, Schallert T (1994) Use-dependent growth of pyramidal neurons after neocortical damage. J Neurosci 14:2140-2152.

Jones TA, Chu CJ, Grande LA, Gregory AD (1999) Motor skills training enhances lesion-induced structural plasticity in the motor cortex of adult rats. J Neurosci 19:10153-10163.
Jurkowitz MS, Litsky ML, Browning MJ, Hohl CM (1998) Adenosine, inosine, and guanosine protect glial cells during glucose deprivation and mitochondrial inhibition: correlation between protection and ATP preservation. J Neurochem 71:535-548.

Katz LC, Shatz CJ (1996) Synaptic activity and the construction of cortical circuits. Science 274:1133-1138.

Kleim JA, Swain RA, Armstrong KA, Napper RM, Jones TA, Greenough WT (1998) Selective synaptic plasticity within the cerebellar cortex following complex motor skill learning. Neurobiol Learn Mem 69:274-289.

Klintsova AY, Greenough WT (1999) Synaptic plasticity in cortical systems. Curr Opin Neurobiol 9:203-208.

Kolb B, Gibb R (1991) Environmental enrichment and cortical injury: behavioral and anatomical consequences of frontal cortex lesions. Cereb Cortex 1:189-198.

Lagerbäck PA, Ronnevi LO, Cullheim S, Kellerth JO (1981) An ultrastructural study of the synaptic contacts of alpha-motoneurone axon collaterals. I. Contacts in lamina IX and with identified alpha-motoneurone dendrites in lamina VII. Brain Res 207:247-266.

Lee JK, Kim JE, Sivula M, Strittmatter SM (2004) Nogo receptor antagonism promotes stroke recovery by enhancing axonal plasticity. J Neurosci 24:6209-6217.

Li S, Overman JJ, Katsman D, Kozlov SV, Donnelly CJ, Twiss JL, Giger RJ, Coppola G, Geschwind DH, Carmichael ST (2010) An age-related sprouting transcriptome provides molecular control of axonal sprouting after stroke. Nat Neurosci 13:1496-1504.

Li S, Strittmatter SM (2003) Delayed systemic Nogo-66 receptor antagonist promotes recovery from spinal cord injury. J Neurosci 23:4219-4227.

Liu BP, Cafferty WB, Budel SO, Strittmatter SM (2006) Extracellular regulators of axonal growth in the adult central nervous system. Philos Trans R Soc Lond B Biol Sci 361:1593-1610.

Lorber B, Howe ML, Benowitz LI, Irwin N (2009) Mst3b, an Ste20-like kinase, regulates axon regeneration in mature CNS and PNS pathways. Nat Neurosci 12:1407-1414.

Luke LM, Allred RP, Jones TA (2004) Unilateral ischemic sensorimotor cortical damage induces contralesional synaptogenesis and enhances skilled reaching with the ipsilateral forelimb in adult male rats. Synapse 54:187-199.

Maier IC, Baumann K, Thallmair M, Weinmann O, Scholl J, Schwab ME (2008) Constraint-induced movement therapy in the adult rat after unilateral corticospinal tract injury. J Neurosci 28:9386-9403.

Marangos PJ, Trams E, Clark-Rosenberg RL, Paul SM, Skolnick P (1981) Anticonvulsant doses of inosine result in brain levels sufficient to inhibit [3H] diazepam binding. Psychopharmacology (Berl) 75:175-178.

Markgraf CG, Kraydieh S, Prado R, Watson BD, Dietrich WD, Ginsberg MD (1993) Comparative histopathologic consequences of photothrombotic occlusion of the distal middle cerebral artery in Sprague-Dawley and Wistar rats. Stroke 24:286-292.

Merzenich MM, Sameshima K (1993) Cortical plasticity and memory. Curr Opin Neurobiol 3:187-196.

Nakagawa S, Guroff G (1973) The uptake of purines by rat brain in vivo and in vitro. J Neurochem 20:1141-1149.

Nithianantharajah J, Hannan AJ (2006) Enriched environments, experiencedependent plasticity and disorders of the nervous system. Nat Rev Neurosci 7:697-709.

Nudo RJ (2007) Postinfarct cortical plasticity and behavioral recovery. Stroke 38:840-845.

Ohlsson AL, Johansson BB (1995) Environment influences functional outcome of cerebral infarction in rats. Stroke 26:644-649.

Oldham MC, Konopka G, Iwamoto K, Langfelder P, Kato T, Horvath S, Geschwind DH (2008) Functional organization of the transcriptome in human brain. Nat Neurosci 11:1271-1282.

Papadopoulos CM, Tsai SY, Alsbiei T, O’Brien TE, Schwab ME, Kartje GL (2002) Functional recovery and neuroanatomical plasticity following middle cerebral artery occlusion and IN-1 antibody treatment in the adult rat. Ann Neurol 51:433-441.

Paxinos G, Watson C (1986) The rat brain in stereotaxic coordinates, Ed 2. Boston: Academic.

Piecharka DM, Kleim JA, Whishaw IQ (2005) Limits on recovery in the corticospinal tract of the rat: partial lesions impair skilled reaching and the topographic representation of the forelimb in motor cortex. Brain Res Bull 66:203-211.

Raineteau O, Fouad K, Noth P, Thallmair M, Schwab ME (2001) Functional 
switch between motor tracts in the presence of the mAb IN-1 in the adult rat. Proc Natl Acad Sci U S A 98:6929-6934.

Rampon C, Tang YP, Goodhouse J, Shimizu E, Kyin M, Tsien JZ (2000) Enrichment induces structural changes and recovery from nonspatial memory deficits in CA1 NMDAR1-knockout mice. Nat Neurosci $3: 238-244$.

Risedal A, Mattsson B, Dahlqvist P, Nordborg C, Olsson T, Johansson BB (2002) Environmental influences on functional outcome after a cortical infarct in the rat. Brain Res Bull 58:315-321.

Rouiller EM, Liang FY, Moret V, Wiesendanger M (1991) Patterns of corticothalamic terminations following injection of Phaseolus vulgaris leucoagglutinin (PHA-L) in the sensorimotor cortex of the rat. Neurosci Lett 125:93-97.

Scott GS, Spitsin SV, Kean RB, Mikheeva T, Koprowski H, Hooper DC (2002) Therapeutic intervention in experimental allergic encephalomyelitis by administration of uric acid precursors. Proc Natl Acad Sci U S A 99:16303-16308.

Scott GS, Cuzzocrea S, Genovese T, Koprowski H, Hooper DC (2005) Uric acid protects against secondary damage after spinal cord injury. Proc Natl Acad Sci U S A 102:3483-3488.

Shen H, Chen GJ, Harvey BK, Bickford PC, Wang Y (2005) Inosine reduces ischemic brain injury in rats. Stroke 36:654-659.

Smith JM, Lunga P, Story D, Harris N, Le Belle J, James MF, Pickard JD, Fawcett JW (2007) Inosine promotes recovery of skilled motor function in a model of focal brain injury. Brain 130:915-925.

Smyth GK, Michaud J, Scott HS (2005) Use of within-array replicate spots for assessing differential expression in microarray experiments. Bioinformatics 21:2067-2075.

Starling RD, Trappe TA, Short KR, Sheffield-Moore M, Jozsi AC, Fink WJ, Costill DL (1996) Effect of inosine supplementation on aerobic and anaerobic cycling performance. Med Sci Sports Exerc 28:1193-1198.

Steinmetz MP, Horn KP, Tom VJ, Miller JH, Busch SA, Nair D, Silver DJ, Silver J (2005) Chronic enhancement of the intrinsic growth capacity of sensory neurons combined with the degradation of inhibitory proteoglycans allows functional regeneration of sensory axons through the dorsal root entry zone in the mammalian spinal cord. J Neurosci 25:8066-8076.
Steward O, Sharp K, Yee KM, Hofstadter M (2008) A re-assessment of the effects of a Nogo-66 receptor antagonist on regenerative growth of axons and locomotor recovery after spinal cord injury in mice. Exp Neurol 209:446-468.

Stirling DP, Liu S, Kubes P, Yong VW (2009) Depletion of Ly6G/Gr-1 leukocytes after spinal cord injury in mice alters wound healing and worsens neurological outcome. J Neurosci 29:753-764.

Tsai SY, Markus TM, Andrews EM, Cheatwood JL, Emerick AJ, Mir AK, Schwab ME, Kartje GL (2007) Intrathecal treatment with anti-Nogo-A antibody improves functional recovery in adult rats after stroke. Exp Brain Res 182:261-266.

van Praag H, Kempermann G, Gage FH (2000) Neural consequences of environmental enrichment. Nat Rev Neurosci 1:191-198.

Volker D, Bate M, Gentle R, Garg M (2000) Oral buprenorphine is antiinflammatory and modulates the pathogenesis of streptococcal cell wall polymer-induced arthritis in the Lew/SSN rat. Lab Anim 34: 423-429.

Whishaw IQ, Pellis SM, Gorny BP, Pellis VC (1991) The impairments in reaching and the movements of compensation in rats with motor cortex lesions: an endpoint, videorecording, and movement notation analysis. Behav Brain Res 42:77-91.

Yang HW, Lemon RN (2003) An electron microscopic examination of the corticospinal projection to the cervical spinal cord in the rat: lack of evidence for cortico-motoneuronal synapses. Exp Brain Res 149:458-469.

Yin Y, Cui Q, Li Y, Irwin N, Fischer D, Harvey AR, Benowitz LI (2003) Macrophage-derived factors stimulate optic nerve regeneration. J Neurosci 23:2284-2293

Zai L, Ferrari C, Subbaiah S, Havton LA, Coppola G, Strittmatter S, Irwin N, Geschwind D, Benowitz LI (2009) Inosine alters gene expression and axonal projections in neurons contralateral to a cortical infarct and improves skilled use of the impaired limb. J Neurosci 29:8187-8197.

Ziv Y, Ron N, Butovsky O, Landa G, Sudai E, Greenberg N, Cohen H, Kipnis J, Schwartz M (2006) Immune cells contribute to the maintenance of neurogenesis and spatial learning abilities in adulthood. Nat Neurosci 9:268-275 